\title{
Jorge Luis Borges e a teologia cristã'
}

\author{
Jorge Luis Borges and the Christian theology
}

Cicero Cunha Bezerra²

RESUMO

Nas primeiras linhas da sua "Historia de la Eternidad", Jorge Luis Borges faz a seguinte observação: "o tempo é um problema para nós, um terrível e exigente problema, talvez o mais vital da metafísica; a eternidade, um jogo ou uma fatigada esperança" (BORGES, 2005, p. 11). A questão que nos conduzirá aqui nesse artigo é: se o tempo é um problema, ou "o" problema metafísico por excelência", o que significa uma história da eternidade e como pensa-la frente aos elementos da teologia cristã presentes na obra borgeana? Para esse artigo nos centraremos, além da "Historia de la Eternidad", particularmente, no "Aleph", na coletânea de contos intitulada "Siete noches" e na "Historia universal de la infâmia".

PALAVRAS-CHAVES: Borges, Literatura, Teologia, Tempo, Eternidade.

ABSTRACT

In the first lines of his "Historia de la Eternidad", Jorge Luís Borges makes the following observation: "time is a problem for us, a terrible and demanding problem, perhaps the most vital of metaphysics, the eternity, a game or a fatigued hope" (BORGES, 2005, p.11). The question that will lead us here in this paper is this: if time is a problem, or "the metaphysics' problem by excellence", and what is the meaning of a history of eternity and how do we think about it in front of the elements of Christian theology present in the Borgean work? For this paper we'll focus in addition to the "Historia de la Eternidad", on the "Aleph", on the collection of short stories entitled "Siete noches" and on the "Historia universal de la infâmia".

KEYWORDS: Borges, Literature, Theology, Time, Eternity.

\footnotetext{
${ }^{1}$ Recebido em 01/11/2017. Aprovado em 31/12/2017.

2 Professor do Programa de Pós-Graduação em Ciências da Religião/UFS. Email: cicerobezerra@ hotmail.com
} 


\section{Considerações iniciais}

No sé qué opinará el lector, de tales conjeturas semi teosóficas. Los católicos (léase los católicos argentinos) creen en un mundo ultraterreno, pero he notado que no se interesan en él. Conmigo ocurre lo contrario; me interesa y no creo. (BORGES, 1974, p. 282)

Jorge Luis Borges (1889-1986) é um desses autores que não cabem em um único campo de saber. Facilmente transita pela filosofia, como quem transita por bibliotecas. Do mesmo modo, mergulha na literatura expondo complexas formulações filosóficas e teológicas. Filho de pai agnóstico e de mãe católica "a la manera argentina", como ele mesmo define, isto é, mais por questão social que teológica (MIGUEZ, 2006, s/p). Borges parece conciliar, em suas obras, a característica de trânsito entre a herança, por parte de mãe, de católicos e metodista que sabiam a Bíblia de cor, e um pai que ele definia como livre pensador.

Se a vida, para Borges, parecia não ter sentido ou pelo menos deveria ser tomada como um "inextricável labirinto de destinos difícil de redução à uma lógica" (LOPRETE, 1985, p. 625), a literatura é tudo que extrapola uma confissão biográfica ${ }^{4}$. Nesse sentido, é preciso encarar o aspecto criador, inventivo e provocador que a obra de Borges permite. Com isso, queremos deixar claro que a análise aqui empreendida também joga, em grande medida, com a tarefa interpretativa de leitor que, como diz Borges, é mais civil e intelectual (1974, p. 289). Para uma aproximação ao tema da eternidade nos centraremos, de modo mais específico, na sua "Historia de la eternidade" visando ressaltar, além da conhecida capacidade de leitura do autor, sua faceta de historiador das ideias que, nessa obra, se evidencia de modo singular a partir das diversas referências à história da filosofia, bem como, mediante passagens que figuram algumas das mais importantes recepções teológica de problemas que delinearam os rumos do pensamento ocidental como é o caso da relação entre tempo, eternidade e trindade.

3 BORGES, J.L. Discursión Leshe D. Weatherhead: After Death (The Epworth Press London, 1942). Irr. Obras completas, 1974, p. 282.

${ }^{4}$ Em nota que abre a edição de suas obras completas, publicada em 1974, Borges dedica à sua mãe Leonor Acevedo Borges, uma confissão memorialista de sua infância, e finaliza: "Aquí estamos hablando los dos, et tout le reste est litterature, como escribió, con excelente literatura, Verlaine” (1974, p. 9). 
Originalmente publicada em 1936, a "Historia de la eternidade" congrega, além do ensaio que dá nome à obra, o artigo "La doctrina de los ciclos" e outros dois, agregados posteriormente, que dizem respeito diretamente à temática que são: La metáfora (1952) e El tempo circular (1943), além dos ensaios "Las "kenningar"', "Los traductores de Las mil y uma noches", "El acercamiento a Almotásim". A análise aqui realizada, pauta-se fundamentalmente na noção de Eternidade, se concentrando na sua peculiar interpretação que associa filosofia e teologia ao campo do fantástico e do maravilhoso.

\title{
Filosofia, Literatura, Religião e intertextualidade
}

Existe um aspecto bastante destacado pela crítica que se debruça sobre a obra de Borges, que consiste no seu aspecto intertextual. Borges, ao costurar textos, transporia o limite do individual colaborando com a ideia da literatura como um saber coletivo (GLANTZ, 2006). Nesse sentido, a "História de la eternidad" é uma constatação do que acabamos de dizer. Afirma Glantz:

\begin{abstract}
A intenção de intertextualidade é delirante e nos é revelado pela vociferação implícita nos títulos, nos contos, nos prólogos - nas alusões falsas dos seus textos, no aparato crítico falaz e, no entanto, acadêmico que os sustentam, nas minuciosas, mas, as vezes, rápidas incursos pelas erudições, em seu contínuo trânsito pelas enciclopédias que iniciam seus relatos e que encarnam seus laços, em sua pertinaz relação com autores do passado, em sua obsessiva visita à filosofia. E mais, a intertextualidade é o corpo da ficção. (idem)
\end{abstract}

Que a construção literária, enquanto tal, se define pela relação intertextual não é novidade, no entanto, o que importa observar, no caso da obra aqui analisada, é a explícita estrutura intertextual que se apresenta como fundamento da escrita e, por sua vez, como caminho que conduz, pelas múltiplas tramas, a uma experiência da verdade que é, antes de tudo, criação. Nisso residiria, segundo Manuel Jesús Muñoz Merchán, a força da liberdade criadora de Borges que suplanta as clássicas distinções entre verdade e ficção, verdade e

\footnotetext{
${ }^{5}$ Artigo disponível na Biblioteca Virtual Universal sem paginação. Conferir: GLANTZ, M, Borges, ficción e
} intertextualidade, Editorial del Cardo, disponível em: http://www.biblioteca.org.ar/libros/300043.pdf 
realidade (MERCHÁN, 2009) . Daniel Omar Perez, por sua vez, aponta para o trabalho de desarticulação realizado por Borges dos argumentos filosóficos. Afirma ele:

Borges desarticula os textos filosóficos em vários momentos mostrando sua instância última como metafórica. Essa é a via da escrita que utilizou, por exemplo, na Historia de la Eternidad (1936), onde o tratamento dos argumentos filosóficos chega a passar da ironia ao humor (2004, p. 14).

Natalia González de la Llana Fernández, em seu estudo “Usos literários de la religión: cuatro cuentos de Borges" destaca a impossibilidade de uma definição segura sobre as crenças pessoais de Borges, no entanto, no "Epílogo de Otras consideraciones" o poeta afirma que seus interesses por ideias religiosas e filosóficas, além de estéticas, são movidos pelo que elas possuem de singular e maravilhoso (BORGES, 1974, p. 775) ${ }^{7}$. Filosofia, teologia, metafísica e literatura compartem o campo do fantástico ${ }^{8}$ como expressões convergentes em uma simbiose capaz de unir, sob um mesmo impulso criativo, o real e a ficção (KAMEL, 2006, p. 9). Uma das passagens publicada na "Notas" é reveladora para o que estamos aqui afirmando. Diz ele:

Compilei algumas vezes uma ontologia da literatura fantástica. Admito que essa obra é uma das pouquíssimas que um segundo Noé deveria salvar de um segundo dilúvio, mas delato a culpável omissão dos insuspeitáveis e maiores mestres do gênero: Parmênides, Platão, João Escoto Eriúgena, Alberto Magno, Spinoza, Leibniz, Kant, Francis Bradley. Em efeito, o que são os prodígios de Well ou de Edgar Allan Poe - uma flor que nos chega do porvir, um morto submetido à hipnose - confrontados com a invenção de Deus, com a teoria laboriosa de um ser que de algum modo é três e que

${ }^{6}$ Artigo disponível na Biblioteca Virtual Universal sem paginação. Versão original publicada em: Espetáculo. Revista de estúdios literários. Univesidad Complutense de Madrid, 2009. Disponível em: http:/ / www.biblioteca.org.ar/libros/150658.pdf .

${ }^{7}$ Sobre a presença da Bíblia na obra de Borges ver a Tese de Doutorado de Gonzalo Salvador Vélez intitulada "Borges y la Biblia. Presencia de la Biblia en la obra de Jorge Luis Borges", Universitat Pompeu Fabra Barcelona, septiembre de 2008, disponível em http:/ / www.tdr.cesca.es/ bitstream/ handle/10803/7447/ tgsv.pdf?sequence=1. Acesso em 23/07/16. O artigo de Lucas Martín Adur Nobile intitulado "Simpatías y diferencias. Borges y la intelectualidade católica argentina en la segunda mitad de la década del veinte" é bastante emblemático no que tange às relações de Borges para com o cristianismo, em particular, sua vertente Argentina. As duas fases, anos vinte (colaborador) e a partir dos anos trinta (crítico) são interessantes para se entender como o conteúdo dos textos cristãos desempenhou papéis importantes na biografia do poeta. Cf. NOBILE, L.M.A. Sociedad y Religion $\mathrm{n}^{\circ} 38$, Vol XXII (2012) p. 14-45

${ }^{8}$ Para uma definição da noção de literatura fantástica, conferir: TODOROV. T. Introdução à literatura fantástica, trad. Maria Clara C. Castelo, São Paulo: Perspectiva, 2003. 
solitariamente perdura fora do tempo? $\bigcirc$ que é a pedra de bezoar ante a harmonia preestabelecida, quem é o unicórnio ante a Trindade, quem é Lucio Apuleio ante os multiplicadores de Budas do Grande Veínculo, o que são todas as noites de Shahrazad próximo a um argumento de Berkeley? Venerei a gradual invenção de Deus; também o Inferno e o Céu (uma remuneração imortal, um castigo imortal) são admiráveis e curisos desígnios da imaginação dos homens (BORGES, 1974, p. 280).

Como se pode constatar, o trânsito entre filosofia, literatura e religião é marcado, precisamente, pelos aspectos fantásticos de suas teorias. Essa mesma impressão temos quando lemos o conto "El indigno" no qual Borges afirma que os elementos euclidianos, presentes em Spinoza, dão somente um ilusório rigor à narrativa fantástica (idem, p. 1029). Dito isso, temos assentado o terreno para que possamos adentrar, de modo mais detalhado, na sua exposição de uma história da Eternidade.

Daniel Ramón Prieto Fernández, ao analisar a ideia de uma metafísica do tempo em Borges, afirma que, em contraposição ao discurso de Paulo de Tarso de que "morremos a cada dia", Borges propõe uma ontologia em que o ser é devir, isto é, morte e nascimento contínuos (FERNÁNDEZ, 2013, p. 479).

Na tradição cristã, Aurélio Agostinho foi quem melhor formulou a questão do tempo no Livro XI das suas "Confissões". Para o Bispo de Hipona, todas as coisas repousam no eterno ato criador de Deus. Diz ele: “Existem, pois, o céu e a terra e proclamam que foram feitos; pois estão sujeitos a mudanças e a alterações" (AGOSTINHO, 2001, p. 224). O tempo se reduz, desse modo, a um instante que é eterno ato criador, enquanto aquilo que se repete infinitamente, mas transitório, dado que sua permanência implica, necessariamente, em seu fim. $\bigcirc$ instante é "passagem" nunca espaço ou lugar. Mais do que passagem, o instante, diria, é presença. Presentificação da vida que repousa sobre a eternidade da criação. No capítulo 17 das "Confissões" lemos: "não podemos dizer com verdade que o tempo existe senão porque ele tende para o não existir" (idem, p. 232).

Dado o fato da análise de Borges centrar-se muito mais na relação tempo-Trindade e eternidade, alguns aspectos radicais, que o texto das "Confissões" permite, escapam aos olhos 
do poeta9. No entanto, Borges prefere retomar as ideias de tempo e eternidade a partir da sua origem mais remota. Os gregos são o foco privilegiado em sua análise. Platão, Plotino e, posteriormente, a tradição cristã, que absorveu a intuição platônica do tempo como "imagem móvel da eternidade" (Timeu, 37d), são questionados e refutados um a um no intuito de preparação para o que Borges chama de sua "teoria particular" da eternidade"|. . Cumpre observar que a análise de Borges, mais do que teológica, expressa sua concepção da literatura como uma experiência estética e, nesse sentido, como bem destaca Julio Juan Ruiz, a ciências sagrada (teologia) possui beleza igual que a matemática (RUIZ, 2013, p. 168)".

A delimitação do tema da eternidade realizada por Borges condiz com o aspecto de "detetive" que sua literatura propõe. Historiar como encontrar pistas que, pese seus desvios, apontam para uma certa unidade interpretativa em que autores como Plotino, Irineu, Agostinho de Hipona (trindade clássica quando nos reportamos às raízes neoplatônicas), se misturam com Paulo de Tarso, Alberto Magno, Tomás de Aquino, entre outros, compondo uma visão, ao mesmo tempo plural e singular, no que se refere à sua tarefa de crítico. A

9 Nos referimos aqui, ao aspecto "místico" que a análise agostiniana, especialmente nas Confissões, permite a partir da associação entre a criação e o ato criador como coeternos e simultâneos. Por não ser objeto da análise de Borges, não desenvolveremos aqui esse tema.

10 É importante não perdermos de vista o fato de Borges, como bem observa Andréa Padrão, ser um autor "inconfiável" e sem pretensão de criar teorias como deixa claro nessa passagem: "Yo no tengo ninguna teoría del mundo. En general, como yo he usado los diversos sistemas metafísicos y teológicos para fines literarios, los lectores han creído que yo profesaba esos sistemas, cuando realmente lo único que he hecho ha sido aprovecharlos para esos fines, nada más. Además, si yo tuviera que definirme, me definiría como un agnóstico, es decir, una persona que no cree que el conocimiento sea posible" (Borges in Vázquez, 1977, p.107) apud PADRÃO, A. A teologia e a literatura de Borges: um diálogo, FERRAZ, S., et al.,orgs. Deuses em poéticas: estudos de literatura e teologia [online]. Belém: UEPA; Campina Grande: EDUEPB, 2008. 364 p. ISBN 978-857879-010-3. Disponível em: http:// books.scielo.org/id/pdkdq/pdf/ferraz-9788578791186-06.pdf . Ainda sobre o caráter transformador que Borges realiza de certas concepções teológicas, ver: DÍAZ, P.N. Los hilos de la trama oscura: la diversidade teológica en la poesia de Borges, EPOS, XXIX (2013) págs. 227-236, disponível em: http:/ / e-spacio.uned.es/ fez/ eserv/bibliuned:Epos-2013-29-5060/Hilos_trama_oscura.pdf Acesso dia 23/07/16.

"Há uma ampla discussão entre os críticos do pensamento de Borges sobre o valor real que a teologia e a filosofia teriam para o poeta. Seriam de fato objetos de interesse enquanto tais ou somente entendidas como literaturas fantásticas? Sobre o tema ver: HINCAPIÉ, A.L. Borges... ¿ Filósofo? Creación literária y filosofia na obra de Jorge Luis Borges (Tese de Doutorado), Cornell University, 2008, disponível em: https:/ / ecommons.cornell.edu/.../2/Borges\%20-_\%20PDF\%20Complete\%2009-17.pdf . Acesso dia 23/07/16. Em entrevista concedida a Laurent Bouvier-Ajam, após negar a possibilidade de uma crença em um Deus pessoal, Borges afirma que a teologia é mais valsa e rica que a literatura fantástica: "Quand on parle des petites inventions de Wells, de Poe ou de Kafka, on voit que la théologie est bien plus vaste et plus riche que la littérature fantastique. La Trinité, par exemple, est bien plus étrange que la Licorne ou que la Chimère. Ces trois personnes qui sont une, c'est très étrange". Cf. Entretien avec Jorge Luis Borges - Propos recueillis par Laurent Bouvier-Ajam le 25 décembre $1982 . \quad$ Disponível em: http:/ / www.electre.com/ widgets/Interview\%2OBorges\%201982f0140c70-f933-4cl0-adb6 cllfcaeeb3a7.pdf .Acesso em 23/06/2016. 
inversão realizada, logo no início da obra, denota sua perspicácia em demarcar a base teórica sobre a qual se moverá ao longo do texto, diz ele: "começarei recordando as obscuridades inerentes ao tempo: mistério metafísico, natural, que deve preceder à eternidade, que é filha dos homens" (idem, p.12).

Como se pode constatar, o problema metafísico, como dirá ele, não é a eternidade, mas o tempo enquanto realidade natural que condiz com a própria condição humana de mortal. Estamos, assim, diante da inversão do pensamento plotiniano, também anunciada nos primeiros parágrafos e, com isso, sua oposição a toda uma larga tradição herdeira do pensamento de Platão e sua distinção, neoplatonizante, entre mundo sensível e inteligível atribuídos, respectivamente, às coisas e às realidades imutáveis.

Mas, em que medida o tempo é um problema vital para o homem? Sem sombra de dúvida, se há uma questão que norteia a história do pensamento ocidental é: como compreender a temporalidade de um mundo que, pese a sua aparente permanência, se mostra fluido e em constante devir? Essa questão obteve diversas respostas em suas múltiplas vertentes (religiosa, mítica, filosófica, literária, teológica, etc.), no entanto, todas parecem apontar para uma mesma perspectiva, a saber: para existência de uma ordem eterna na qual as coisas, em sua temporalidade repousariam e, em sendo assim, obteriam sua estabilidade. Para a consolidação dessa visão, dois autores foram decisivos: Platão e Plotino.

\section{Platão e sua herança plotiniana}

Borges parte da ideia de que o primeiro pensador a tomar a eternidade como fundamento oposto ao mundo sensível, foi Platão ${ }^{12}$. Platão, por uma questão que diríamos ser teórica, foi obrigado a propor uma concepção do tempo que, necessariamente, não condizia com aquilo que Ihe fundamentaria, isto é, o eterno. A teoria do conhecimento platônica, baseada em "ideias" ou "paradigmas" que são em si mesmos imutáveis, impunha ao pensador a exigência de postular uma divisão entre dois níveis: o eterno ou o chamado "mundo das ideias" e o temporal ou "o mundo da aparência".

\footnotetext{
${ }^{12}$ Embora no Prólogo ele reconheça o papel de Parmênides de Eléia.
} 
Segundo Borges, Platão, no diálogo "Timeu", fundou uma concepção realista das ideias tão afastada de nosso ser que se tornou impossível crer em alguma interpretação sua. Ironiza o poeta afirmando não crer nem na sua própria interpretação dos arquétipos verdadeiros de Platão. A consequência do realismo platônico foi o fortalecimento do seu oposto, isto é, o nominalismo que se converteu em uma premissa geral, um axioma que todos praticam sem saber. O poeta, ao modo aristotélico de uma crítica à teoria das ideias de Platão, afirma: "examinamos uma eternidade que é mais pobre que o mundo" (2005, p. 23). Como se pode observar, Borges reproduz uma crítica à teoria da participação platônica já realizada por Aristóteles em sua "Metafísica" quando o estagirita questiona o fato de que, ao postular a duplicidade de mundo, Platão teria que sustentar a existência, no mundo inteligível, de tantas formas (paradigmas) quantas realidades existentes no mundo inteligível o que, ao que parece, não figuraria em sua teoria de modo explícito ${ }^{13}$.

Plotino, intérprete de Platão, como ele mesmo se define nas "Enéadas", elevou a estatuto supremo o modelo platônico. Sua concepção do Uno como absolutamente transcendente e do múltiplo como geração contínua da unidade que permanece una, pese a multiplicidade das coisas, gerou um sistema hipostático em que a eternidade assume sua face de completa oposição à matéria. A eternidade, como diz Borges, se tornou o imóvel e terrível museu dos arquétipos platônicos (idem, p. 16). Uma vez mais a teoria das ideias é o foco central. Borges a resume do seguinte modo: "os indivíduos e as coisas existem na medida em que participam das espécies que os incluem e que são suas realidades permanentes" (idem, p. 18). Esta descrição nos conduz a existência do individual que participa da ideia universal e é assim, seguindo as consequências do pensamento plotiniano, que temos ilustrada o conceito de tempo como "imagem móvel do eterno", isto é, um rouxinol que canta em minha janela é a repetição, no tempo, de uma "forma (Rouxinol) " que cantou, canta e cantará infinitamente. Dito de outro modo, o rouxinol é "o imortal que se mantém na reposição dos indivíduos" (idem, p. 19).

Borges é, às vezes, irônico e também complacente com a concepção metafísica dos universais eternos. A triangularidade, a Necessidade, a Razão e todas as demais ideias que apontam para a existência de uma universalidade que abarcaria todas as coisas individuais, são

${ }^{13}$ Sobre a relação matéria e forma, no aspecto apresentado por Borges, ver: ARISTÓTELES, Metafísica, 987 b5. 
tomadas, por ele, como "comodidades" que não poderiam ser intuídas sem o auxílio da morte, da febre ou da loucura (idem, p. 20). $\bigcirc$ poeta não perde a oportunidade e acrescenta a eternidade, expressa no despedaçamento temporal, como exemplo maior. A eternidade tomada como vã esperança é, provavelmente, uma herança do "lúcido" Schopenhauer ${ }^{14}$ que Borges cultivou como influência. Diz ele: "Antes, me interessou a teologia, mas dessa fantástica disciplina (e da fé cristã) me desviou, para sempre Schopenhauer, com razões diretas" (1972, p. 64).

Não há, portanto, por parte do poeta, nada que justifique melhor a descrença em uma doutrina hipostática da eternidade do que a própria concepção de uma correspondência na qual figura somente formas isoladas que enquanto "espelhos" não refletem, em absoluto, seus reflexos (cópias). E como se dá a recepção, da doutrina das ideias, pela tradição cristã?

\section{A teologia cristã e o tempo}

Nenhuma das várias eternidades que propuseram os homens - a do nominalismo, a de Irineu, a de Platão é uma agregação mecânica do passado, do presente e do povir. É uma coisa mais simples e mais mágica (2005, p.14]

$\mathrm{Na}$ "Historia de la Eternidad" o cristianismo ocupa lugar central. Sob a forma da Trindade, a eternidade teve que ser justificada em sua unidade-trina ${ }^{15}$. A eternidade das três pessoas, diz Borges, não foi um simples paramento, foi uma resolução, uma arma com data e autor. Com Irineu de Lyon a geração do Filho pelo Pai e a emissão do Espírito pelos dois foram explicadas graças ao deslocamento da temporalidade, no seu aspecto de sucessão, passado, presente e futuro. A geração é um só ato. $\bigcirc$ cristianismo não só refunda a ideia do eterno que transcende de modo absoluto o tempo, mas a torna dogma na figura da coeternidade das pessoas divinas. Diz Borges: "Irineu se propôs salvar o monstro, e o

${ }^{14} \mathrm{Em}$ "Otras inquisiciones" lemos: "Al releer esta nota, pienso en aquel trágico Philipp Batz, que se llama en la historia de la filosofía Philipp Mainlánder. Fue, como yo, lector apasionado de Schopenhauer. Bajo su influjo ly quizá bajo el de los gnósticos) imaginó que somos fragmentos de un Dios, que en el principio de los tiempos se destruyó, ávido de no ser" (BORGES, 1974, p. 702).

${ }^{15}$ Sobre o tema ver: SPANNEUT, M. Le Stoicisme des Pères de l'Église, de Clément de Rome a Clément d' Alexandrie,. Paris: Editions du Seuil, 1957. 
conseguiu. Sabemos que era inimigo dos filósofos; apoderar-se de uma de suas armas e voltála contra eles deve ter-lhe causado um prazer belicoso" (idem, p. 29).

A consequência direta do postulado da eternidade como atributo divino, já que com Irineu tudo está no Verbo que é criador e coeterno com a criação, foi o isolamento, uma vez mais, do eterno como o transcendente absoluto. Dentro da tradição cristã, Borges ressalta o papel decisivo de Escoto Eriúgena que, ao contrário da tradição ortodoxa, pensou um Deus indeterminável e, portanto, fora de toda atribuição ou categoria. Deus não é e, enquanto tal, congrega em si todas as criaturas (idem, p. 32). Esta, não passa de um mero nome que não corresponde à realidade divina. Não foi por casualidade que sua obra foi condenada e queimada na fogueira. Hector Yankelevich, em seu artigo La Gnose de Borges, aponta para a filiação do poeta, contra o dogma central do Cristianismo, com o gnosticismo. Diz ele:

Borges dá ao pai uma transcendência absoluta, sem interseção alguma, o que elimina todo recurso a uma Providência, ao perdão, à Teodiceia no sentido da história. $\bigcirc$ pai não somente é inatingível, mas não participa de nada do que ocorre no mundo (1997, p. 142).

poeta é direto ao afirmar que somente um pesadelo poderia ter parido a ideia de uma articulação entre um pai, um filho e um espectro articulados em um mesmo organismo. Uma verdadeira teratologia intelectual (2005, p. 25). Próximo da ideia de Trindade o inferno perde todo horror. A saída teológica encontrada por Irineu de pensar a geração como "um só ato sem tempo" (idem, 26) é algo que culmina na veneração, mas elimina toda discussão. Até aqui temos a análise da ideia de eternidade a partir da história da filosofia que, em última instância, gira em torno da discussão entre realismo e o nominalismo, isto é, da relação entre a eternidade pensada em seu aspecto substancial e a eternidade enquanto atributo ou conceito. Ambas, para Borges, serviram para negar, em certo aspecto, a própria vida. "Viver é perder tempo: nada podemos recuperar ou guardar a não ser sob a forma de eternidade" (idem, p. 34), diz Borges, citando indiretamente Jorge Santayana. Frente ao percurso teológico-metafísico que de uma maneira ou de outra elevou a eternidade à abstração vazia de uma substância ou de um nome. 
Na base de uma unidade em que passado, presente e futuro coincidem em um mesmo instante estaria, segundo Borges, a nostalgia dos homens de uma vida feliz sub specie aeternitatis (idem, p. 36). Não resta dúvida da adequação criativa que Borges realiza entre as grandes quimeras e, nessas, a Trindade como uma capacidade da arte de "combinar". Na discussão intitulada "Sobre el dublaje", Borges trata da infinita capacidade de combinação que os gregos tiveram associando figuras humanas e animais gerando quimeras, bem como os teólogos do II século a inextricável figura da Trindade (1974, p. 283).

Nosso autor não ignora em una "vindicación de la Cabala" o problema de fundo que norteia a concepção de uma consubstancialidade entre as pessoas da Trindade. Diz ele: "Se o Filho não é também o Pai, a redenção não seria uma obra diretamente divina" (idem, p. 210). Metáforas de uma unidade que se mantém como sopro de um dogma de um ato sem tempo (idem, p. 210). Frente ao que ele nomeia de "desejo" de uma "pátria perdida", Borges aponta para uma "teoria pessoal da eternidade" (2005, p. 37). Em que consiste? O que Borges narra, como experiência particular de eternidade, é uma vivência sem Deus, sem arquétipos, evanescente, como ele diz, bastante irracional e sentimental para o pensamento.

O relato, feito de memória, ocupa duas páginas e faz alusão a uma outra obra publicada em 1928 intitulada "El idioma de los Argentinos" (1928). Para uma melhor exposição, faço um breve resumo da narrativa intitulada "Sentirse en muerte". O relato segue os tons de uma experiência extática típicas das narrativas místicas: "Desejo registra aqui uma experiência que tive há algumas noites atrás: ninharia demasiada evanescente para que se chama aventura; demasiada irracional e sentimental para pensamento" (2005, p. 37).

Nas jogadas de xadrez que a escritura borgeana executa, leitores acostumados às artimanhas do autor podem se perder nas tramas de um pensamento que, pelo exercício literário, incorpora temas sem compromissos maiores, além dos esforços humanos em dar respostas às questões tão radicais como a vida e a morte, o tempo e a eternidade, faces de um desejo, em que as metáforas apontam para um outro lugar que, enquanto tal, é outro da própria vida.

O fato, portanto, de Borges descrever sua "pessoal teoria" sob a base de um "sentimento" que não se configura como "pensamento" é, por um lado, ironia de alguém que joga com o lugar comum das tradições por ele historiadas, mas, também, é uma maneira, 
diríamos, de se inserir no espaço ficcional da criação que não se pretende verdade, mas memória, que, enquanto tal, é também esquecimento, graças aos "acidentes do tempo" (idem, p. 37). Diz ele: "não quero significar, assim, o meu bairro, o preciso âmbito da infância, mas suas misteriosas imediações (...) o contrário do conhecido, suas costas (...)" (idem, p. 38). A descrição das casas, contempladas por uma visão já cansada, é de pobreza e beleza, "era o mais pobre e o mais belo" (idem, p. 38).

Tudo se passou em Barracas, uma localidade descrita como pouco visitada por Borges. Era noite e o poeta decidiu caminhar, ou como ele diz, caminhar e recordar. Uma caminhada sem rumo, propositalmente, ao acaso. Ao acaso não, mas por casualidade. Sua escolha pelo sem destino o privou de uma caminhada ao acaso. $\bigcirc$ que the guiou foi o que ele chama de "um tipo de gravitação familiar" que o levou a um bairro em que palavra e realidade se confundiam em um só tempo. Era o bairro da sua infância. $\bigcirc$ aspecto das casas, baixas e humildes, mais que pobreza trazia felicidade. Casas que não ousavam, nas palavras de Borges, aproximar-se das ruas; figueira que se ensombrecia sobre a calçada, os portõezinhos, mais altos que as linhas alongadas das paredes, e que pareciam trabalhados com a mesma substância infinita da noite. Tudo isso levou a seguinte conclusão: era o mesmo de trinta anos atrás.

mais curioso é que a tipicidade tornava tudo irreal. $\bigcirc$ vertiginoso silêncio quebrado somente pelo também intemporal ruído dos grilos fez com que o poeta contemplasse a simplicidade e se sentisse conhecedor abstrato do mundo. Naquele instante, o tempo cedeu espaço a verdadeira eternidade. Eternidade que, ao contrário de algo contraposto ao tempo, se funda na aparência mesma de um momento em que o ontem e o hoje convergem em uma unidade-na-diferença. Distintamente de um eterno retorno do mesmo, o que se repete é sempre o outro que, na repetição, aponta para a permanência enquanto finitude e morte. Estamos diante do que Deleuze nomeou de “jogo da diferença e da repetição" em que Borges foi quem mais longe chegou (DELEUZE, 1988, p. 116). Essa intuição vislumbrada em forma de êxtase revelou, para Borges, que a vida é pobre demais para não ser também imortal. Talvez nessa pobreza resida a intuição de um Deus que, como lemos na entrevista feita por Álvaro Alves de Farias, vacila entre a existência e não existência de uma experiência estética (2001, p. 53). 


\section{Considerações finais}

A título de conclusão diríamos que a análise realizada por Borges, sob o título de História, bem que poderia ser renomeada, parafraseando e invertendo Guimarães Rosa ${ }^{16}$, como Estória, isto é, como narrativa literária que, enquanto tal, traz no seu seio a metáfora ${ }^{17}$ como elemento central. Não nos esqueçamos que para Borges, "a história universal é a história de algumas metáforas" (1974, p. 636). Sendo assim, historiar metáforas consiste no exercício criativo que ousa jogar não somente com a intertextualidade, mas radicaliza-se ao colocar em questão a própria realidade dos intertextos (DOMÍNGUEZ, 2005, p. 27). Nesse contexto, a eternidade, e todos os temas e autores a ela associados, compõem um diálogo marcado pela erudição, representada pelas diversas citações, tanto de autores, como de críticos e, também, por uma estratégia que, para se realizar enquanto obra, permite que o autor, no "Prólogo"18, reconheça outros caminhos possíveis sem, no entanto, alterar o corpo geral dos argumentos, o que nos leva a pensar no aspecto plural de se "narrar" uma história que, enquanto tal, está sempre composta por labirintos múltiplos, cabendo-nos o papel de caminhar por entre suas imagens narrativas. Sua crítica à teologia não deve, portanto, ser tomada como uma aversão teórica aos conteúdos da fé, mas paradoxalmente, o que neles são questionáveis, e que constituem, precisamente, o objeto de seu interesse.

Finalmente, a escolha por uma arquitetônica argumentativa, historicamente consistente, já que não resta dúvida de que, por exemplo, a teoria da ideia de Platão, ao contrário de orgânica e dinâmica, foi interpretada por muitos, inclusive por Santo Agostinho, como expressão da eternidade das Formas divinas, revela seu profundo conhecimento e sua capacidade de recorte que, enquanto tal, delimita os caminhos que compõe a obra.

16 Guimarães Rosa abre o Prefácio de "Tutaméia" com a seguinte afirmação: "A estória não quer ser história. A história, em rigor, deve ser contra a História" (2001, p. 29).

${ }_{17}$ Sobre o papel da linguagem como metáfora conferir: BEZERRA, C.C. Jorge Luis Borges: a linguagem como experiência estética. Miscelânea, Assis, vol.9, jan./ jun, 2011.

${ }^{18}$ Nos referimos aqui à passagem em que Borges, no Prólogo da "História de la Eternidad" lamenta ter associado as Formas de Platão às peças imóveis de museu. É bem verdade que as implicações oriundas da compreensão das Formas como vivas, poderosas e orgânicas $(2005$, p. 7) alteraria, substancialmente, os argumentos e conclusões sustentadas ao longo da obra. 


\section{Referências}

AGOSTINHO, A. Confissões. Tradução e notas de Arnaldo do Espírito Santo, João Beato e Maria Cristina de Castro-Maia de Sousa Pimentel, Lisboa: Casa da Moeda, 2001.

ARISTÓTELES. Metafísica. Trad. Valentín García Yebra, Madrid: Gredos, 1990.

BORGES, J.L. Obras completas. Buenos Aires: Emecé Editores, 1974.

BORGES, J.L. Historia de la Eternidad. Buenos Aires: Emecé Editores, 2005.

DE FARIAS, A. A. Borges, o mesmo e o outro. São Paulo: Escrituras, 2001.

DELEUZE, G. Diferença e repetição. Rio de Janeiro: Graal, 1988. Acesso online disponível em: https:/ / ayrtonbecalle.files.wordpress.com/2015/07/ deleuze-g-diferenca-e-repeticao.pdf

DOMÍNGUEZ, Martha Elia A. Borges y la intertextualidad. In: Contribuciones desde Coatepec, n. 9, jul./ dez., 2005. Disponível em: http:/ / www.redalyc.org/pdf/281/28150903.pdf

FERNÁNDEZ, D. R. P. Metafísica del tempo en la obra de Jorge Luis Borges (Tese de Doutorado), Madrid: Universidad Autónoma, 2013, disponível em: https:/ / repositorio.uam.es/bitstream/handle/10486/661952/ prieto_fernandez_daniel_ramon.p df?sequence $=1$. Acesso dia 23/07/16.

KAMEL, Fawzia. Borges, Averroes y Aristóteles: Literatura y filosofía. In: Extravío. Revista electrónica de literatura comparada, $n^{\circ} 1,2006$, p.1-14.

LOPRETE, Carlos. Literatura Hispanoamericana y Argentina. Buenos Aires: Editorial Plus, 1985.

MÍGUEZ, C. P. Aniversario de la muerte de Borges. Entrevista inédita con Borges: "Soy un anarquista conservador". Madrid: El país. Disponível em: http:/ / cultura.elpais.com/ cultura/2016/ 06/14/actualidad/1465900278_877505.html

PEREZ, Daniel Omar. A interpretação de J. L. Borges sobre a metáfora no texto filosófico. In: Revista de Filosofia, Curitiba, v. 16 n.19, p. 11-26, jul./ dez. 2004.

RUIZ, Julio Juan. Temática Teológica em Tres Cuentos de Jorge Luis Borges. Estudos Hispanicos XXI, Wroclaw, 2013. 
YANKELEVICH, H. La Gnose de Borges, Variaciones Borges 4, 1997. Disponível em: https:/ / www.borges.pitt.edu/sites/default/ files/0407.pdf . Acesso em 23/07/16. 